\title{
Assessment of factors to receiving food aid in the Caprivi region of Namibia: A factor analysis approach
}

\author{
J. M. Nyambe ${ }^{1 \star}$ and A. Belete ${ }^{2}$ \\ ${ }^{1}$ Department of Agricultural Economics and Animal Production, University of Limpopo, P/Bag X1106, Sovenga, 0727 , \\ South Africa.
}

Accepted 15 June, 2012

\begin{abstract}
Now than ever before, rural communities in the Caprivi region of Namibia are relying more on food aid. This shows that something has gone wrong with their sources of livelihood. This paper seeks to reveal the factors that predispose one to receive food aid. A sample size of 253 respondents was randomly selected from Kabbe, Katima Rural and Linyanti Constituencies. The three constituencies constitute the flood plains. Factor analysis was used to empirically identify patterns of relationships among observed factors. The results obtained show that five factor components, namely, capacity to farm, climate risk awareness, household economic status, past economic opportunities, and household labour with eigenvalues of $\geq 1$ are invaluable to eligibility to food aid. These factors have proven to be responsible for about $68 \%$ of the total variance and are thus, vital for predisposing rural households to receiving food aid in the study area. By addressing and taking measures on the variables of the factor components that expose households to food aid, rural households in the study area would most likely stay away from relying on food aid.
\end{abstract}

Key words: Food aid, factor components, rural households.

\section{INTRODUCTION}

\section{Agriculture in the Caprivi region of Namibia}

Namibia has a dualistic agricultural sector. In the south of the Veterinary Cordon Fence (VCF) are commercial livestock farmers while in the Northern part of the VCF are communal farmers. The VCF is in place to control the spread of food and mouth disease which occurs frequently in the North and North eastern parts of the country. Maize meal is highly consumed in the North eastern part while millet is the main staple crop in the far Northern regions of Namibia. Cattle, goats and sheep are reared by commercial farmers for local markets and for export to the EU and South Africa. Cattle and goats are common in communal areas. Sheep do not adapt to

${ }^{*}$ Corresponding author. E-mail: mrnyambe@gmail.com. Tel: +264 817155654, +27 735959063. north of the VCF due to high rainfall that causes worm infections and other diseases. Far in the rural outskirts of the Caprivi region, agriculture is the main livelihood strategy. Whilst agriculture is the mainstay of the subsistence economy, there are also coping strategies in place, namely, fishing, mini grocery shops, and selling of natural resource products such as reeds, poles, grass and firewood. Todaro (1997) reported on why people concentrate on agriculture in developing countries. Low income compels people first to satisfy food, shelter and clothing needs. Both underemployment and open unemployment are to blame for reduced standards of living in developing countries (Todaro, 1997). In line with the quest for improving food security needs of rural people, Kalindan et al. (2000) advises that the remedy lies in addressing issues that confronts small-scale farmers. In a study conducted in Madagascar, Park (2006) observes that in areas where subsistence farming is practiced with prior knowledge of low income yields, few households which are large net sellers are common. 
Again, in such environments, purchases of grain are a common thing. This observation is similar to findings made in China (Park, 2006). These observations are important in that they reflect the unique characters of subsistence farmers in developing countries and how their characteristics could turnout in changing climate risk environment. Like in all the regions north of the Veterinary Cordon Fence (VCF), land ownership in the Caprivi region is of communal tenure system. In this case, traditional leaders serve as custodians to administering land allocation. Even so, the government remains the owner of the land. On population statistics, Namibia has a human population of about 2.2 million but of this, the northern part of the VCF has more than half of it. Thus, it tells that pressure on land ownership is increasing. The area north of the VCF is at most $40 \%$ of the total geographic area of the entire country. The south of the VCF is arid and most of the land is fenced as private property with the big chunk of it belonging mainly to commercial farmers. There are various reasons why people own land. Land ownership could be for the purpose of investing in it for profitable farming motives. Land can be owned for precautionary motive which falls within the family's desire to operate it on subsistence purposes. With high income or with more income diversification opportunities, the demand for land ownership especially, for subsistence farming tends to decline (González-Vega et al., 2003). The Caprivi region receives the highest annual rainfall compared to all the other regions of Namibia. This region receives an annual average rainfall of $653 \mathrm{~mm}$ (Samsamwater, 2011; Ministry of Works and Transport, 2011). In recent years, it has been observed that frequent floods occur but droughts are also common. Of late, a greater part of the study area has frequently been inundated with flood water.

\section{LITERATURE REVIEW}

There are key constraints faced by rural households in the Caprivi region. They include inter alia the lack of hard and soft-type of infrastructure and also issues of postharvesting activities. In a study by Makhura and Wasike (2003), infrastructure is classified in terms of its economic and social role. In their study, they referred to economic infrastructure as public amenities and transport related fixed -type of investments. Social infrastructure refers to education, health and recreational facilities. Our view is that economic and social infrastructure can fall into two categories of either soft or hard infrastructure. Hard, as in terms of fixed investments such as roads, electric pylons and buildings whereas soft infrastructure includes among others electronic cash transmission system and email facilities. These are less to come by in the rural areas in the Caprivi region. Schools do exist but health facilities are distant while roads are in poor state. With an exception of the Linyanti constituency, Kabbe and Katima rural areas suffer from lack of road and piped water respectively. Other constraints faced by rural farming households in the Caprivi region relates to postharvesting activities. Randela (2003) in a study of postharvesting problems faced by small-scale farmers in Limpopo Province suggests the need for small-scale farmers to be integrated in the supply chain in which their produce gets channeled. In the rural Caprivi, communal farmers are detached from the supply chain. In fact there are no organized markets to which they belong. It is only recently that the Government of the Republic of Namibia has constructed silos for storage of local harvests in the regions north of the VCF including in Caprivi.

Usually, maize farmers battle to get their produce to the urban market at Katima Mulilo. Maize buyers at Katima Mulilo are: Eagle Meal, Kamunu Supermarket and Kalinki Supermarket (Rings). Cattle sellers are slightly better in that their buyers would visit rural crush pens and source the animals they need. The main cattle buyer is the Meat Corporation (Meatco). Even with these buyers, there is no formal relationship that exists between them and rural farmers in the Caprivi region. In a study that intended to reveal the potential for milk goats in the Eastern Cape Province of South Africa, Belete et al. (1999) advices that dairy goat production under good management can become a profitable undertaking especially for rural dwellers. The findings also suggest the need for a formal market where rural dairy goat farmers can sell their milk. This view supports the need for establishing formal or organized markets for rural farm producers.

In a study on small-scale farmers in Ethiopia, Beyene (2008) found that small farms that are not productive suffer from an income squeeze. The ultimate consequence is that the owners tend to focus on other off-farm activities to supplement an income deficit from agriculture. This scenario explains why some small-scale farmers engage in other non-farm economic activities. Other farmers can take advantage of food shortages by intensifying their crop production activities to generate income as opposed to venturing into non-farm opportunities. In view of this notion, Mabuza et al. (2009) have argued that for Swaziland to receive food aid during the past five years is due to declining agricultural harvests resulting from sporadic droughts. They found low domestic stock as asking for imports to meet the domestic demand. In turn, the quest for imported maize to quell down the increased demand often fall to the appetite of other local farmers who makes profit from the high demand for maize in the country. It is not only agricultural produce that suffers from lack of integration in the supply chain in Caprivi region. Fish, which is one of the coping strategies for many rural households especially, in the Kabbe and Katima Rural Constituencies, often fetch low income for sellers due to spoilage. Spoilage occurs because there is lack of electricity and refrigeration facilities in the constituencies 
where fish is caught. Those involved in catching fish earns income from selling it but also from it being a nutritional diet. Most of the fish sold at the urban market at Katima Mulilo is sourced from the Zambezi River and from the Liambezi Lake. With an improved infrastructure and an integrated supply chain, when not sold, fish could be preserved and or processed using modern technology. As it is the case now, fish that fail to be bought is preserved using traditional methods of seasoning it with salt and then drying it on the sun. This method is not efficient in that bugs would still bore in and destroy the fish which then forces the owner to sell it at a loss. Besides the constraints that have been stated, the positive side is that all the old pensioners at the age of 60 receive an old age pension. At the current rate, each pensioner receives 500 Namibian dollars which is an equivalence of 500 Rand. In a study by Pelham (2007) on old age pension fund in Lesotho, Namibia and South Africa, it was found that Namibia and South Africa provides the old age fund under the pretext that the aged are economically vulnerable. There is no other requirement to accessing an old age pension in Namibia besides being a citizen and having reached the age of 60 . The old age pension fund is nonetheless a vital social net to addressing poverty in rural aged people. However, whether receiving an old age pension fund and food aid have an effect on farming decisions is not what this paper seeks to address. Intuition would suggest that these provisions may or may not influence those of at least 60 years rural dwellers to ignore their agricultural livelihood. Away from old age and old age pension fund, the provision of food aid remains critical in the Caprivi region. The rolling-out of food aid in the study area intensified from the 2002/2003 harvesting season until 2007 harvesting season. Against this background, this paper seeks to reveal what predisposes rural communities to become eligible to receiving food aid in the flood plains. This consideration should be viewed at the household level perspective. In other words, there is a question that arises which is 'what should be harnessed as a capacitating factor so that a rural household may continue to exist without having to rely on food aid'?

\section{MATERIALS AND METHODS}

\section{Study area}

The study was conducted in what is called the flood plains which is the constituencies of Kabbe, Katima Rural and Linyanti. The difference between the Linyanti constituency and the other two constituencies is that rural farmers in that constituency have crop fields located in the riverine area but also in the high semi-forest area. As such, when pushed by climate related factors especially, flood, some farmers in the Katima Rural but mainly those in the Linyanti Constituency can avoid riverine fields for high semi-forest fields. The study uses data gathered from 253 respondents in the Kabbe, Katima Rural and Linyanti Constituencies who were randomly selected by means of stratified and two-stage cluster sampling. A structured questionnaire was administered to the respondents by face to face interviews.

\section{Model}

For this study, Factor analysis (FA) functions was used. Factor analysis can help to reduce many variables to a more meaningful number of variables and also to assist with analyzing interrelationships among variables (Chioma, 2009; Darlington, 1997). Several authors have used FA in their studies. The preference to use FA is found in its applicability to scenarios that cut-across various disciplines. In the first place, FA was invented more than 100 years ago by Charles Spearman who studied mental ability. One of the basic tenets of FA is to examine the pattern of correlations between observed measures and to study the strength of the relationship between factors and observed measures. The constructs that are highly correlated regardless of the positive or negative sign are usually considered to belong to one underlying factor (DeCoster, 1999). Although, FA is a useful tool for analyzing complex data, however, it is expected that it is handled with care to prevent ambiguity in interpreting results (Hare-Bruun et al., 2011). Other authors who used FA include Hill and Petty (1995) in their study of employability skills and they found FA to be a useful analytical tool. Those confronted with seeking to understand entangled behaviours of variables often resort to FA as their analytical method of choice (Rummel, 1970). Attempting to unravel the mystery of user information satisfaction, Doll et al. (1995) employed FA and it proved to be robust in pointing out the underlying factor relationships and enabled the authors to improve the previously existed model used in user information satisfaction. Mathematically, factor analysis can be challenging and it uses technical terms which are unique. Mathematically, a factor analysis model looks as follows:

$Z_{r}=(\lambda) t(\operatorname{lrt} Q t)+\operatorname{lr} v Q r v$

Where:

$\mathrm{Z}=$ Standardised variable,

$\mathrm{L}=$ Factor loading,

$Q=$ Common factor or factor score

$r=$ Index for variables

$\mathrm{t}=$ Index for factors, and

$v=$ The unique portion.

The extraction method used is Principal Component Analysis and for rotation, varimax with Kaizer Normalisation was used. Factor analysis is a reduction technique which has been used in many studies. The factor process has to test the null hypothesis $\mathrm{H}_{0}$ that the original correlation matrix is an identity matrix.

\section{RESULTS}

At the outset, we indicated that the target population resides in the rural areas. Socio-economic structures of rural households need to be understood first before going into factor analysis. These socio-economic considerations of respondents appear in Table 1.

The average age in years of the heads of the households is 47 . The average household size is 5 members and it coincides well with census data released by the National Planning Commission (2001) which puts the average household size in Caprivi at 5 members. The average 
Table 1. Socio-economic statistics of respondents.

\begin{tabular}{lccccc}
\hline Parameter & N & Minimum & Maximum & Mean & Std. deviation \\
\hline Age of respondent in years & 253 & 21.00 & 74.00 & 47.3004 & 15.96365 \\
Education level in years & 253 & 0.00 & 14.00 & 6.2648 & 3.67707 \\
Household size & 253 & 1.00 & 10.00 & 5.0514 & 1.97236 \\
Total farm size owned in ha & 253 & 2.00 & 20.00 & 6.0711 & 3.46337 \\
Farming experience in years & 253 & 0.00 & 59.00 & 19.1818 & 14.29503 \\
Actual monthly income & 253 & 200.00 & 3200.00 & 628.7747 & 333.82060 \\
Available household labour in numbers & 253 & 2.00 & 6.00 & 3.0514 & 1.06594 \\
\hline
\end{tabular}

Table 2. Explained variance for extracted factors.

\begin{tabular}{cccc}
\hline Principal component & Eigenvalues & Initial \% of variance & \% of variance due to rotation \\
\hline$X_{1}$ & 3.050 & 25.415 & 24.689 \\
$X_{2}$ & 1.650 & 13.752 & 12.015 \\
$X_{3}$ & 1.256 & 10.464 & 11.533 \\
$X_{4}$ & 1.184 & 9.870 & 10.750 \\
$X_{5}$ & 1.016 & 8.470 & 8.983 \\
\hline
\end{tabular}

Table 3. Rotated component matrix for the factor analysis process.

\begin{tabular}{|c|c|c|c|c|c|}
\hline \multirow{2}{*}{ Parameter } & \multicolumn{5}{|c|}{ Component } \\
\hline & $\mathrm{X}_{1}$ & $X_{2}$ & $\mathbf{X}_{3}$ & $\mathbf{X}_{4}$ & $X_{5}$ \\
\hline Whether one owned land or not & 0.906 & & & & \\
\hline Farming experience in years & 0.882 & & & & \\
\hline Knowledge of common climate risk factors & 0.872 & & & & \\
\hline New problems & 0.672 & & & & \\
\hline Satisfaction with early warning system in place & & 0.803 & & & \\
\hline Objectives for tilling the land & & -0.637 & & & \\
\hline Education level in years & & 0.478 & 0.446 & & \\
\hline Household size & & & 0.703 & & \\
\hline Actual monthly income & & & 0.667 & & \\
\hline Abandoned economic activities & & & & 0.844 & \\
\hline Available household labour in numbers & & & & & 0.743 \\
\hline Common diseases & & & & & 0.703 \\
\hline
\end{tabular}

land size owned by a household is 6 ha. In this paper, 12 observed variables were entered in the Factor analysis simulation process. The results appear in Table 2.

Out of the 12 variables that were entered into the factor process, 5 factor components were extracted using Kaizer's criterion of selecting factors with eigenvalues that are $\geq 1$. Initially, the 5 factor components which are $\mathrm{X}_{1}, \mathrm{X}_{2}, \mathrm{X}_{3}, \mathrm{X}_{4}$, and $\mathrm{X}_{5}$ yielded the \% of variance of 25.415 , $13.752,10.464,9.870$ and 8.470 respectively. Factor analysis produced a determinant of 0.015 , a KaiserMeyer-Olkin Measure of Sampling Adequacy of 0.650, Bartlett's test of sphericity Chi-Square of 1037.912 with 66 degrees of freedom and the significance of 0.000 .
Table 3 shows 12 factors that are grouped in five-factor components. These are as a result of the orthogonal process which was done to improve the factor structure. Factors can only belong to particular factor-components if they are highly loaded on the given component. This means that when factors are highly loaded on a component, such factors would technically share some relationship. In Table 3 , the factors and the factorcomponents to which they belong are: owning land, farming experience, knowing common climate risk factors, and new problems were highly loaded on the $X_{1}$ factor component. Satisfaction with early warning system was highly loaded on the $\mathrm{X}_{2}$ factor component. Still on 


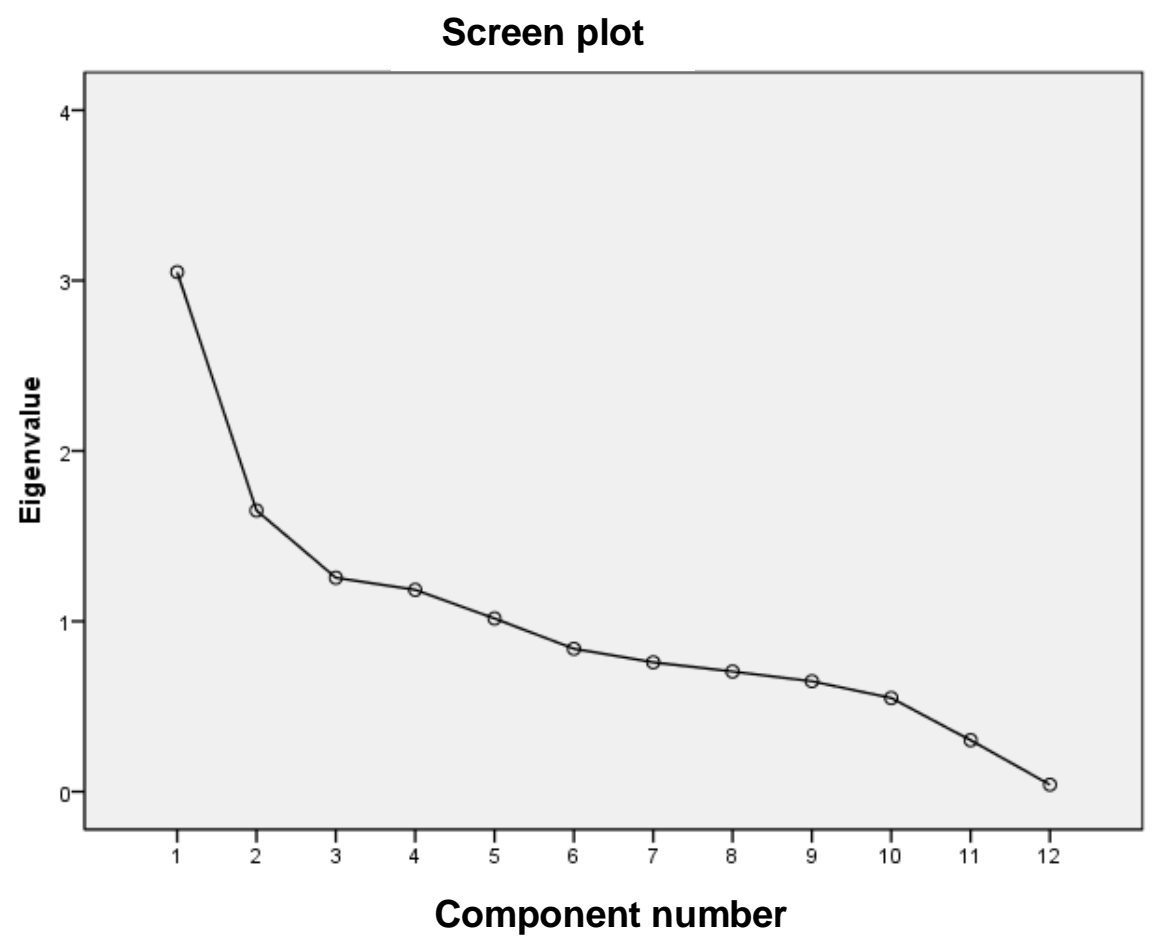

Figure 1. Extracted five factor components.

this factor component is the educational level of the head of the household, which was not highly loaded but was significant; objectives for tilling the land has a negative correlation. Household size and actual monthly income are well loaded on $X_{3}$ factor component. Abandoned economic activities which in the past helped the household as coping strategies are highly loaded on $\mathrm{X}_{4}$ factor component while availability of household labour and common diseases that affects the household is highly loaded on the $X_{5}$ factor component. The graphical performance of the extracted factor components is presented in Figure 1. As demonstrated in Figure 1, the first 5 factor components are clearly the main influencers of the variance while the remaining ones are not that influential compared to the former. This is demonstrated by the pattern of the curve from the first factor that shows an increasing decline to the second and third factor and a tilt towards the fourth factor and a steady decline to the fifth factor. From thereon, a different pattern appears from the sixth factor to the tenth and again going onwards to the twelfth factor.

\section{DISCUSSION}

Since the determinant that obtained 0.015 is greater than 0.00001 , it proves that there is no multicollinearity in the data and as such, the data is acceptable with the use of factor analysis. On the communalities, it comes out clear that the absence of communalities that reached 0.9 after extraction satisfies that there are no identities in the matrix. The Kaiser-Meyer-Olkin Measure of Sampling Adequacy has also confirmed that the patterns of correlations are compact and thus factor analysis is suitable for the analytical purpose. With the use of Bartlett's Test of Sphericity to test the $\mathrm{H}_{0}$, it was confirmed that the original R-matrix is not an identity matrix. Conversely, $\mathrm{H}_{0}$ is $\neq 0$. The acceptable significance value should have been any value $\leq 0.05$ and with the current outcome of 0.000 , it is statistically significant. As reflected in Table 2, that due to rotation, the initial 5 factor components yielded 24.689, 12.015, $11.533,10.750$ and $8.983 \%$ of total variance respectively. These factor components are not orthogonal to one another but within each factor component the variables are correlated. As a result of the interrelationships among the variables that load on identified factor components $X_{1}, X_{2}, X_{3}, X_{4}$, and $X_{5}$, there is a need to label these factors. They are thus, named capacity to farm, climate risk awareness, household economic status, past economic opportunities, and household labour fitness respectively. It has been demonstrated that these 5 factor components are responsible for predisposing rural households to relying on food aid. As identified in Maslow's hierarchy of needs, when a household has no land, it lacks one of the critical factors of production. This goes together with farming experience. A household that rely more on crop farming for its livelihoods can benefit more when it has experience in farming. Climate risk factors can cause a serious drawback to crop farming and livestock 
production.

As such a rural household in the study area should know signs of bad weather and be associated with early warning systems in place. This may prevent wasteful use of scarce inputs such as seeds and related labour factor from being used in an activity that will not advance some economic benefits to a rural farming household.

In an attempt to understand what predisposes rural households to receiving food aid in the study area, it transpired now than ever before, that rural communities in the study area have been receiving more food aid. On the policy side, the Namibian drought policy identifies some existing weaknesses when it comes to assisting farmers who are in need. This means that rural farmers should be assisted with seeds in times of serious need. When suffering from consequences of serious drought, rural farmers can be provided with food parcels. However, past experience shows that there are often administrative and logistical challenges to distributing large amounts food parcels. There is no means-test to identifying who the vulnerable are as opposed to the better-placed rural farmers. This has led to applying the provision of the drought policy by a blanket approach in which everyone in the area that is targeted receives food parcels. On the side of commercial farmers, they often receive crop insurance subsidies when disaster strikes (Ministry of Agriculture, Water and Rural Development, 1997). The problem that comes out clearly with regard to the application of the drought policy is that it discriminates against rural farmers north of the VCF in that only commercial farmers can be assisted with crop insurance.

Beyond policy documents is a need for access to predictable weather conditions. Therefore, understanding and having access to early warning systems which in this case is access to radio can help a rural farming house hold to escape from losing its entire own livelihood support mechanisms to climate risk factors. However, this can only be true when there is reliable predictions and dissemination of such information on all media platforms available to rural households. When these are not in place, a rural household may be forced to rely on food aid resulting from losses to its livelihood system. In a study done in Ghana by Campbell (2004), it was also confirmed that rainfall which catalyses climate risk factors could impose limits on rain-fed crop farming. Adaptation by a farmer in the context of environmentally-based factors is arguably an important element when farming to sustain livelihoods and should thus not be ignored (Campbell, 2004). In light of this, understanding weather related signals especially from an early warning systems perspective is crucial to a rural household whose main livelihood strategy is agriculture. Attaining a reasonable education level is also pertinent in the strife to stay away from relying on food aid. The more educated a person is, the better they can read and interpret warnings but also search for other ways to survive before destructive factors strikes. Household size more educated a person is, the better they can read and interpret warnings but also search for other ways to survive before destructive factors strikes. Household size and income are closely related in terms of consumption theory. Thus, households with more members require more income to feed the members when compared to a household with few members. Thus, income generating opportunities and sustaining livelihoods that provides food to a household are both pertinent to survival of a rural household of $\geq 5$ members. Some of the past economic activities which helped rural households should be looked at and if needed, lessons should be drawn from them for future policy intervention. In the same vein, rural household labour is necessary to the sustenance of livelihoods. The labour which a rural household in the study area requires may not necessarily be skilled as in modern terms but should be readily available to engage in the livelihood and coping strategies to keep it alive. With regard to the prevalence of diseases, rural households in the study area should remain informed of the contagious diseases and the medium of spread of these diseases. Otherwise, a household that in the past coped in various circumstances may fail to do so when its members are infected with deadly diseases.

\section{Conclusion}

Factor analysis has been used to detect the structure of the data. The same has been instrumental in clasping the initial variables into few ones of relative nature. The five factor components responsible for predisposing rural households in the study area are capacity to farm, climate risk awareness, household economic status, past economic opportunities, and household labour fitness. For a development assistance that seeks to wean rural households in the study area from having to rely on food aid to be effective, these factor components need to be understood in terms of how they predispose rural households to food aid. This requires further detailed study as to how each of the identified factors exposes rural households to receiving food aid.

For a policy maker, investing in educational needs of the rural households, investing more in the early warning system and educating the rural households on the signals from the early warning system, finding ways to introduce income generating projects, investing in health facilities, and documenting past economic activities of rural households with the aim of drawing lessons from those activities and improving on some of them can but prevent rural households from having to fall for food aid. The drought policy needs to be revised to align it to the real situation on the ground so that it may also include crop insurance assistance to communal farmers. Sustaining lives of people on handouts should not be encouraged. If allowed to continue, the beneficiaries can easily abandon economic activities that helped them in the past and then 
rely on food aid.

\section{REFERENCES}

Belete A, Kadzere CT, Nyamapfene K (1999). The potential for commercial milk goat production in the arid Eastern Cape regions: Economic analysis of the performance indicators. J. Agrekon 38(1):117.

Beyene AD (2008). Determinants of off-farm participation decision of farm households in Ethiopia. J. Agrekon 47(1):140-161.

Campbell MO (2004). The role of socio-environmental networking in the sustainability of rain-fed agriculture in the coastal savannah of Ghana. Geo. J. 61:79-88.

Chioma NJ (2009). Application of factor analysis to data on improved cassava varieties cultivated in Nigeria. Afr. J. Math. Comput. Sci. Res. 3(11):270-274.

Darlington RB (1997). Factor analysis. [Online] Available at: http://www.psych.cornell.edu/Darlington/chrono.htm.

DeCoster J (1999). Overview of factor analysis. Available online at: http://www.stat-help.com/factor.pdf.

Doll JW, Raghunathan TS, Lim JS, Gupta WP (1995). A confirmatory factor analysis of the user information satisfaction instrument. Information Syst.ems Res.earch, 6(2):177-188.

González-Vega C, Southgate D, Rodríguez-Meza J (2003). Rural poverty, household responses to shocks and agricultural land use: Panel results for El Salvador. USA: The Ohio State University.

Hare-Bruun H, Togo P, Andersen LB, Heitmann BL (2011). Adult food intake patters are related to adult and childhood socioeconomic status. J. Nutr. 141:928-934.

Hill RB, Petty GC (1995). A new look at selected employability skills: A Factor Analysis of the occupational work ethic. J. Vocat. Educ. Res. 20(4):59-73.

Kalinda T, Filson G, Shute J (2000). Resources, household decision making and organisation of labour in food production among smallscale farmers in southern Zambia. J. Dev. South. Afr. 17(2):165-174.

Mabuza ML, Hendriks SL, Ortmann GF, Sithole MM (2009). The impact of food aid on maize prices and production in Swaziland. J. Agrekon 48(1):85-105.

Makhura MN, Wasike WSK (2003). Patterns of access to rural service infrastructure: The case of farming households in Limpopo Province. J. Agrekon 42(2):129-143.

Ministry of Agriculture, Water and Rural Development (MAWRD) (1997). National Drought Policy. Windhoek: Republic of Namibia.

Ministry of Works and Transport (2011). Namibia rainfall performance at specified places - April 2011. Windhoek: Government of the Republic of Namibia.
National Planning Commission (2001). Census 2001. Windhoek: Government of the Republic of Namibia.

Park A (2006). Risk and household grain management in developing countries. Econ. J. 116:1088-1115.

Pelham $L$ (2007). The politics behind the non-contributory old age social pensions in Lesotho, Namibia and South Africa. CPRC working paper No. 83. United Kingdom: Chronic Poverty Research Centre.

Randela R (2003). The incidence of post-harvest problems among small-scale farmers in surveyed in three regions of the Limpopo region. J. Agrekon 42(2):163-180.

Rummel JS (1970). A summary of Rummel's applied factor analysis. Available online at: http://www.hawaii.edu/powerkills/UFA.HTM\#APP.

Samsamwater (2011). Annual rainfall calendar. Accessed on November 8, 2011.

Todaro MP (1997). Economic Development. USA: Addison Wesley Longman Limited. 